\title{
O direito à tutela jurisdicional efetiva e a aplicação dos meios atípicos de execução
}

\author{
The right to effective jurisdictional guarantee and the application of atypical means of execution \\ El derecho a la garantía jurisdiccional efectiva y la aplicación de medios de ejecución atípicos
}

Recebido: 17/03/2021 | Revisado: 24/03/2021 | Aceito: 29/03/2021 | Publicado: 08/04/2021

\author{
Laís Silva Zimiani \\ ORCID: https://orcid.org/0000-0002-3489-5557 \\ Universidade Paranaense, Brasil \\ E-mail: laiszimiani@gmail.com \\ José Miguel Garcia Medina \\ ORCID: https://orcid.org/0000-0002-3669-5145 \\ Universidade Paranaense, Brasil \\ E-mail: medina@medina.adv.br \\ Cassio de Paula Xavier \\ ORCID: https://orcid.org/0000-0003-1373-3943 \\ Universidade Paranaense, Brasil \\ E-mail: cassio.xavier@edu.unipar.br
}

\begin{abstract}
Resumo
O Código de Processo Civil brasileiro prevê no artigo 139, inciso IV, a possibilidade de aplicação das medidas executivas atípicas de forma subsidiária aos métodos executivos típicos. Os meios executivos atípicos são instrumentos criativos e poderosos, que podem causar transtornos substanciais ao executado, razão pela qual devem ser aplicados somente quando em consonância com os princípios fundamentais e setoriais da execução, assim como pela legislação e jurisprudência nacionais. O dispositivo legal é indispensável para a concessão do direito fundamental à tutela jurisdicional efetiva pelo Estado-juiz, mas não pode ser aplicado de forma indiscriminada e descriteriosa, até porque os meios atípicos de execução não possuem a mesma previsibilidade garantida na aplicação dos meios executivos típicos. A pesquisa foi realizada por meio da identificação de conceitos, normas e princípios fundamentais de direito e foi guiada pelo método indutivo, com revisão bibliográfica específica, assim como pela análise legislativa e jurisprudencial sobre o tema.
\end{abstract}

Palavras-chave: Processo de execução; Medidas típicas; Medidas atípicas; Tutela jurisdicional; Efetividade.

\begin{abstract}
The Brazilian Civil Procedure Code provides in article 139, item IV, allowing the application of atypical executive measures in a subsidiary manner to typical executive methods. Atypical executive means are creative and powerful instruments that can cause substantial disruption to the executed, which is why they should be applied only when in line with the fundamental and sectoral principles of execution, as well as with national legislation and jurisprudence. The legal provision is indispensable for the granting of the fundamental right to effective judicial protection by the State-judge, but it cannot be applied in an indiscriminate and discretionary manner, considering that the atypical means of execution do not have the same guaranteed of predictability in the application of typical executive means. The research was carried out through the identification of concepts, norms and fundamental principles of law and was guided by the inductive method, with specific bibliographic review, as well as by the legislative and jurisprudential analysis on the theme.
\end{abstract}

Keywords: Execution process; Typical executive means; Atypical measures; Jurisdictional protection; Effectiveness.

\section{Resumen}

El Código de Procedimiento Civil brasileño prevé en el artículo 139, inciso IV, la posibilidad de aplicar medidas ejecutivas atípicas de manera subsidiaria a los métodos ejecutivos típicos. Los medios ejecutivos atípicos son instrumentos creativos y poderosos que pueden causar perturbaciones sustanciales a los ejecutados, por lo que deben aplicarse solo cuando estén en consonancia con los principios fundamentales y sectoriales de ejecución, así como con la legislación y jurisprudencia nacionales. La disposición legal es indispensable para el otorgamiento del derecho fundamental a la tutela judicial efectiva por parte del juez-Estado, pero no puede ser aplicada de manera indiscriminada y discrecional, sobre todo porque los medios atípicos de ejecución no tienen la misma previsibilidad garantizada en la aplicación de medios ejecutivos típicos. La investigación se llevó a cabo mediante la identificación de conceptos, normas y principios fundamentales del derecho y se guió por el método inductivo, con revisión bibliográfica específica, así como por el análisis legislativo y jurisprudencial sobre el tema.

Palabras clave: Proceso de ejecución; Medios ejecutivos típicos; Medios ejecutivos atípicos; Protección jurisdiccional; Eficacia. 


\section{Introdução}

A previsão de medidas executivas atípicas, pelo Código de Processo Civil de 2015, amplia o espectro de poderes do juiz e configura tema relevante para a comunidade jurídica, despertando a atenção e gerando intensa produção da doutrina e da jurisprudência brasileira sobre $\mathrm{o}$ assunto.

$\mathrm{Na}$ análise do assunto, importante considerar que o dever do Estado-juiz está concentrado em conceder a tutela jurisdicional efetiva ao exequente, desde que limitado à aplicação da norma jurídica, por meio dos princípios processuais e constitucionais relativos ao processo de execução, assim como às peculiaridades do caso concreto.

Enquanto parte da doutrina entende que a aplicação das medidas executivas atípicas traduz uma potencialização do art. 139, IV do CPC e pode culminar em interpretação com resultados positivos para esfera da execução, outra parte afirma que a previsão ilimitada de poderes ao juiz poderia significar uma "carta branca ao arbítrio", com o perigo de restrição aos direitos fundamentais.

O Tribunal de Justiça do Paraná vem implementando a aplicação das medidas executivas atípicas, observando-se, em todo caso, a garantia ao contraditório substancial e a fundamentação da decisão judicial. O Superior Tribunal de Justiça também regulou casos relacionados à aplicação de tais medidas, que deve ser feita subsidiariamente, pontuando ainda, a necessidade de perquirir sobre o caso concreto, tornando imperativa a necessidade de constatação de patrimônio excutível em adequação aos princípios da execução e da busca pela efetivação da tutela jurisdicional.

É evidente que o artigo 139, inciso IV do CPC amplia a gama de possibilidades para a concessão da tutela jurisdicional efetiva, mas não deve ser utilizada como justificativa de decisões arbitrárias e autoritárias. Não é lícito que o juiz vire um "inventor criativo de normas", de acordo com sua consciência, sem critérios ou limites para sua atuação, vez que sua atividade deve ser a de aplicar a norma ao caso concreto, sendo-lhe vedado substituir o legislador.

\section{Metodologia}

A problematização da pesquisa se insere no âmbito de constatação de insuficiência das medidas típicas constante do Código de Processo Civil e sobre a necessidade de adoção e aplicação das medidas executivas atípicas na contemporaneidade, perquirindo-se sobre os critérios e limites legais para que a norma seja aplicada de forma proporcional, razoável e justa, sem que restrinja os direitos e garantias fundamentais dos jurisdicionados.

O estudo tem caráter descritivo, ou seja, a pesquisa é qualitativa, pois visa a compreensão ampla do fenômeno que está sendo estudado. Nessa linha, considera-se que todos os dados da realidade são importantes e devem ser examinados, vez que o ambiente e as pessoas nele inseridas devem ser olhados holisticamente: não são reduzidos a variáveis, mas observados como um todo (Godoy, 1995, p. 62)

A pesquisa foi norteada, também, pelo método indutivo, cuja aproximação dos fenômenos é direcionada para planos cada vez mais abrangentes, indo das constatações mais particulares às leis e teorias (conexão ascendente); método que considera o conhecimento como baseado na experiência; a generalização deriva de observações de casos da realidade concreta e são elaboradas a partir de constatações particulares (Pereira et. al, 2018, p. 28), conforme é possível verificar pela análise legal e jurisprudencial relacionada à matéria.

Desta forma, a pesquisa tem como parâmetro a utilização de revisão bibliográfica, análise legislativa e jurisprudencial sobre o assunto, sendo que a investigação é realizada por meio da identificação de conceitos, normas e princípios fundamentais que denotam sua relevância e utilidade para o direito processual civil brasileiro. 


\section{Resultados e Discussão}

A Lei de Introdução ao Direito Brasileiro (LINDB), em seu artigo $5^{\circ}$, prevê que na aplicação da lei, o juiz deve atender aos fins sociais a que ela se dirige e às exigências do bem comum, assim como o artigo $8^{\circ}$ do Código de Processo Civil reforça essa necessidade ao estabelecer que o juiz, ao aplicar o ordenamento jurídico, deve atender aos fins sociais e às exigências do bem comum, além de resguardar e promover a dignidade da pessoa humana, observando a proporcionalidade, a razoabilidade, a legalidade, a publicidade e a eficiência.

Em relação à eficiência, destaca-se a previsão constitucional acerca do direito à uma prestação jurisdicional adequada, efetiva e tempestiva (CF, art. $5^{\circ}$, XXXV e LXXVIII), de modo que o legislador tem o dever utilizar-se de mecanismos processuais com real aptidão para dar concretude à tutela satisfativa. Em caso de ausência de previsão, cabe ao Poder Judiciário aplicar os direitos constitucionais fundamentais, por meio da aplicação imediata e independente de intermediação legislativa.

Na mesma linha, o CPC prevê em seu artigo $4^{\circ}$ que as "partes têm o direito de obter em prazo razoável a solução integral do mérito, incluída a atividade satisfativa". Assim, se as tutelas dos direitos (necessidades no plano do direito material) são diversas, as técnicas processuais devem a elas se adaptar. O procedimento, a sentença e os meios executivos, justamente por isso, não são neutros às tutelas (ou ao direito material), e por esse motivo não podem ser pensados a sua distância (Marinoni, 2008, p. 240-241).

Havendo algum ato certificador de um direito como uma sentença, ou algum ato cuja eficácia lhe seja equiparada, a execução será a atividade processual (sempre forçada) destinada a transformar em realidade prática aquele direito, para satisfação de seu titular. Quando se funda em título executivo judicial o procedimento será o de cumprimento de sentença, conforme artigos 513 a 538 do Código de Processo Civil, sendo a ele aplicado subsidiariamente o disposto no Livro II da Parte Especial (art. 771) (Câmara, 2020, p. 321).

O modelo baseado na tipicidade das medidas executivas tende a alcançar resultados na medida em que as situações de direito material e os problemas que emergem da sociedade sejam parecidos, conforme afirma Medina (2020, p. 908). Nesses casos, é até mesmo conveniente a previsão de medidas similares para as hipóteses em que problemas parecidos se reproduzam, a fim de que se observe em relação àqueles que estejam em uma mesma situação de direito material um procedimento também similar.

A adoção do princípio da tipicidade das medidas executivas dá ao executado algum grau de previsibilidade acerca dos modos de atuação executiva admissíveis, já que a existência de um rol expresso de medidas executivas permite antever de que modo a execução se realizará. Diversamente ocorre quando adotado, pelo sistema, o princípio da atipicidade das medidas executivas (Medina, 2020, p. 1.099).

Cabe destacar que as medidas executivas se desenvolvem: a) pelo meio de coerção, que é um mecanismo empregado pelo Estado-juiz para constranger o executado, psicologicamente, para que satisfaça o crédito exequendo (astreinte, prisão civil e protesto de título executivo ou anotação do nome do devedor em cadastros de devedores inadimplentes) e pelos meios de sub-rogação e, b) pelo meio de sub-rogação, quando o Estado-juiz desenvolve atividade que substitui a atuação do executado, produzindo o resultado prática equivalente (busca e apreensão de um bem para entregá-lo ao exequente) (Câmara, 2020, p. $324)$.

Nesse contexto, ressalta-se que o Código de Processo Civil de 2015 ampliou os poderes do juiz em relação ao processo executivo, conforme o artigo 139, instituindo outros modos de natureza coercitiva indireta para auxiliar na satisfação do crédito, assim como manteve as medidas coercitivas diretas e indiretas previstas na legislação processual civil de 1973.

Verifica-se que o Código de Processo Civil reforça a potencialidade no cumprimento específico das obrigações a partir da possibilidade interpretativa de alargamento de meios aptos ao cumprimento das decisões judiciais, estes representados 
pelas medidas de execução indiretas, sobretudo na modalidade atípica (JÚNIOR; FAIRBANKS, 2019. p. 188), ao prever que deve o juiz dirigir e determinar "todas as medidas indutivas, coercitivas, mandamentais ou sub-rogatórias necessárias para assegurar o cumprimento de ordem judicial, inclusive nas ações que tenham por objeto prestação pecuniária" (art. 139, inciso IV) (Guimarães, 2020).

Contudo, para Marinoni, Arenhart e Mitidiero (2017, p. 284) existe falta de rigor técnico na redação do inciso IV do artigo 139 do CPC, uma vez que existe excesso nas expressões empregadas ('medidas indutivas, coercitivas, mandamentais ou sub-rogatórias'), na medida em que as medidas coercitivas são espécie de medidas indutivas (as medidas indutivas podem ser de pressão positiva, quando se oferece uma vantagem para o cumprimento da ordem judicial, ou coercitiva, quando se ameaça com um mal para a obtenção da satisfação do comando). Há também confusão de categorias, já que o efeito mandamental - ao lado do efeito executivo - é o efeito típico de ordens judiciais (que veiculam medidas indutivas e sub-rogatórias). Essa falta de rigor técnico, segundo os autores, não compromete a intenção do preceito, que é dotar o magistrado de amplo espectro de instrumentos para o cumprimento das ordens judiciais, inclusive para tutela de prestação pecuniárias (art. 536).

O ordenamento jurídico reconhece, portanto, a necessidade de satisfação efetiva e específica do direito inadimplido como um verdadeiro direito fundamental na Corte Europeia de Direito Humanos, conforme leciona Anne Leborgne (2009, p. $01)$ :

Le droit de l'exécution forcée, c'est-à-dire, l'ensemble des voies de droit offertes à um cráncer pour venir à bien de la résistance de son débiteur, devrait être le droit de l'effectivité. Cést au demeurant en ayant perçu cela, que les juges de la cour européenne des droits de lómme ont élevé le droit à l'execution du créancier au rang de droit fondamental, em 1997, en rattachant au droit au procès équitable.

Desta forma, ao instituir outros modos de natureza coercitiva indireta para auxiliar na satisfação do crédito, houve uma evidente flexibilização do processo por meio da possibilidade de adoção de medidas executivas atípicas pelo juiz, reforçando a existência do direito fundamental do exequente à satisfação efetiva e específica do direito inadimplido.

\subsection{Princípios do processo de execução e a adoção do modelo atípico de execução}

O processo de execução, assim como as demais modalidades de procedimentos judiciais, é regido por importantes princípios fundamentais, que transcendem a esfera da execução, tais como: a dignidade da pessoa humana, a legalidade, o devido processo legal, a isonomia, o contraditório e ampla defesa, a publicidade, a motivação judicial, a razoável duração do processo, a boa-fé, a cooperação, a proporcionalidade e a razoabilidade.

Na doutrina, há autores que também apontam como princípios setoriais ou informativos do processo de execução, instrumentos próprios da execução, que têm como conteúdo destacado a função jurisdicional, quais sejam: patrimonialidade, autonomia, resultado ou especificidade, menor onerosidade ao devedor, disponibilidade, título, tipicidade e atipicidade dos meios executivos, lealdade e desfecho único. Alguns desses princípios não são específicos do processo de execução, mas nele se manifestam com realce (p.ex., o da lealdade processual). Outros são desdobramentos de princípios mais abrangentes. A menor onerosidade, p.ex., rigorosamente, é elemento do critério da proporcionalidade (Medina, 2020, p. 1013).

Em relação aos princípios fundamentais, é de especial relevância o reconhecimento do contraditório, da motivação e da cooperação no processo executivo. No processo de execução, a garantia do princípio do contraditório ou na atividade executiva é constatada, pela "participação". Os sujeitos processuais participam e devem cooperar (e colaborar) entre si na obtenção do resultado executivo.

A motivação judicial (art. 93, IX, CF), assim como a cooperação devem estar, presentes no processo executivo, especialmente, quando se reconhece a possibilidade da aplicação de medidas atípicas de execução, até porque a falta da motivação adequada, com a aplicação da proporcionalidade e razoabilidade, pode dar ensejo às arbitrariedades quando do 
apontamento de medida atípica eficaz para a satisfação do crédito exequendo.

Por outro lado, como princípio setorial, a execução de forma menos gravosa ao executado está expressamente disposta no artigo 805 do CPC e estabelece que quando por vários meios identicamente idôneos o exequente puder promover a execução, o juiz mandará que se faça pelo modo menos gravoso para o executado, ainda que o exequente tenha indicado a forma mais onerosa (art. 798, II, CPC). O juiz pode agir de ofício, pressupondo-se a existência de várias técnicas processuais igualmente idôneas para a realização do direito do exequente. Esse princípio está intimamente ligado ao direito à tutela jurisdicional adequada e efetiva do exequente (art. $5^{\circ}$, XXXV, CF e 797 do CPC) (Marinoni, 2017, p. 893).

Como antes se disse, no caso está-se diante de elemento do critério da proporcionalidade. Isso fica claro no próprio art. 805, parágrafo único, do CPC "ao executado que alegar ser a medida executiva mais gravosa incumbe indicar outros meios mais eficazes e menos onerosos, sob pena de manutenção dos atos executivos já determinados.” Diante disso, afirma José Miguel Garcia Medina (2020, p. 1013) que "as medidas executivas devem ser realizadas observando-se a menor onerosidade (ou menor restrição possível) da medida executiva e a máxima efetividade (ou do resultado) da execução, que nada mais são que elementos do critério da proporcionalidade".

Interessante verificar que, o princípio da cooperação (art. $6^{\circ}$, CPC) em conjunto com o princípio da menor onerosidade (art. 805, CPC), evidencia que ao alegar a existência de meio menos gravoso, o ônus de provar a existência de outros meios tão eficazes quanto o empregado cabe ao executado, sendo que em caso de ausência de demonstração, o juiz pode rejeitar, de plano, a alegação.

O alcance do resultado útil, célere e efetivo não depende da prática de atos isolados, mas da participação e do diálogo entre os sujeitos do processo (Dialogverfahren), para a construção de uma solução justa. A cooperação traduz um dever plurilateral de colaboração entre todos os sujeitos processuais, verdadeira necessidade, em vista da realidade do processo civil global, sendo que não visa apenas o fim de uma disputa, mas o fim efetivo do litígio por meio de uma solução justa e que atenda ao interesse de ambas as partes (Araújo, 2016, p. 177).

Além do fato de que o processo deve ser ético, pautado na boa-fé e na cooperação entre todos os sujeitos do processo, tal como exortam as normas fundamentais do CPC, a execução civil é balizada, portanto, em duas diretivas fundamentais: (1) uma de que a execução é prestada em favor do exequente (art. $4^{\circ}$, art. 139, IV, art. 797), ou seja, tem por objetivo satisfazer o credito exequendo, e, a (2) outra de que essa satisfação não pode ser além do necessário, valendo-se sempre dos meios processuais menos gravosos (art. 776, art. 805, art. 518, art. 520, I, II, II, IV, art. 139, IV, etc.) (Rodrigues, 2020, online).

De acordo com o princípio da tipicidade das medidas executivas, a esfera jurídica do executado somente poderá ser afetada por formas executivas taxativamente estipuladas pela norma jurídica. Trata-se de princípio que existe para satisfazer a exigência de garantir a intangibilidade da esfera de autonomia do executado, que somente poderá ser invadida pelos mecanismos executivos expressamente previstos em lei (Medina, 2020, p. 1.099).

O princípio da atipicidade dos meios executivos supera a ideia de que o juiz poderia proceder somente com os meios executivos tipificados, ou seja, "o CPC estruturou um sistema concertado de medidas executivas típicas e atípicas, variando conforme a natureza da prestação executiva" (Didier; Cunha, Braga, 2017, p. 100).

Em relação à execução por quantia certa fundada em título extrajudicial, prepondera o princípio da tipicidade das medidas executivas (cf. arts. 824 e 825 do CPC), em sentido diverso, em relação à execução de decisão que reconhece a existência de dever de fazer, impera o princípio da atipicidade das medidas executivas (cf. art. 536, caput e $\S 1^{\circ}$ do CPC). Há, ainda, as hipóteses de incidência do critério da atipicidade de modo supletivo, para o caso de não serem suficientes as medidas executivas típicas, previstas na lei processual, nos termos do art. 139, IV do CPC/2015 (Medina, 2020, p. 908).

Os meios executivos atípicos são autorizados pelo CPC, artigos 139, IV, 297 e 536, § $1^{\circ}$, com cláusulas gerais processuais executivas que abriram margem para atuação mais ativa do juiz na satisfação e solução do conflito, autorizando a 
utilização de meios e técnicas mais efetivas. A norma flexibilizou a execução, em especial as prestações pecuniárias, adotando a atipicidade como regra subsidiária, ou seja, se não for possível a satisfação do direito por meios tipificados, surge a possibilidade de adoção de medidas inominadas.

A cláusula geral de atipicidade possui compatibilidade com os princípios constitucionais e processuais civis, conforme aduz Alexandre Freitas Câmara (2016, p. 88):

\begin{abstract}
A legitimidade constitucional da cláusula geral de atipicidade de meios executivos provém de sua compatibilidade com dois princípios constitucionais: o princípio da tutela jurisdicional efetiva (art. $5^{\circ}, \mathrm{XXXV}$ ) e o princípio da eficiência (art. 37). Aliás, vale a pena recordar que ambos esses dispositivos constitucionais são reafirmados como normas fundamentais do processo civil, como se vê̂ pelos arts. $3^{\circ}$ e $8^{\circ}$ do CPC de 2015. Por força da garantia constitucional de tutela jurisdicional efetiva estabelece-se uma exigência de que o resultado prático do processo coincida, tanto quanto possível, com o resultado prático que se produziria se o direito substancial fosse espontaneamente realizado. É, em outras palavras, uma garantia constitucional de que haverá a maior coincidência possível entre o resultado prático do processo e aquilo a que o titular do direito material faz jus.
\end{abstract}

Em conjunto com os princípios aplicáveis ao processo executivo e pela interpretação emanada da norma, as medidas atípicas devem ser utilizadas em ultima ratio, ou seja, quando se esgotarem as medidas legais previstas. Nesse sentido, o Fórum Permanente de Processualistas Civis (FPPC), no enunciado de no 12, com referência expressa aos arts. 139, IV, 523, 536 e 771 do CPC, aduz que "a aplicação das medidas atípicas sub-rogatórias e coercitivas é cabível em qualquer obrigação no cumprimento de sentença ou execução de título executivo extrajudicial." Contudo, resguarda a aplicação das medidas atípicas de forma subsidiária às tipificadas, "com observação do contraditório, ainda que diferido, e por meio de decisão à luz do art. $489, \S 1^{\circ}$, I e II".

Uma das hipóteses que justifica o emprego de medidas atípicas de execução é quando o executado ostenta elevado padrão de vida e não indica bens penhoráveis para adimplemento da obrigação, fundada em título executivo extrajudicial. Para Medina, as premissas iniciais a serem observadas, podem ser representadas pela seguinte equação: importância do bem jurídico tutelado + qualidade da cognição judicial realizada = intensidade das medidas executivas (Medina, 2020, p. 908).

O uso de medida coercitiva como a multa periódica poderia justificar-se, assim como o uso de medidas como a indisponibilidade de bens e direitos (cf. art. 185-A do CTN, Lei 5.172/1966, na redação da LC 118/2005), ou em casos mais extremos, até mesmo a intervenção judicial na empresa poderá ter lugar (art. 102 e ss. da Lei $12.529 / 2011)$.

A imposição de medidas atípicas é necessária, inclusive, naqueles casos conhecidos no cenário brasileiro como “devedor-ostentação”, facilmente constatável por meio das mídias sociais. Trata-se daquele indivíduo que deve, não nega - e também não precisa (o sistema no mais das vezes ineficiente o protege) -, mas não paga, o que não o impede de levar uma vida de luxo, incompatível com sua situação de suposta falta de bens, enquanto o credor sofre com a falta de bens penhoráveis (por vezes ocultados em nome de terceiros, os "laranjas", nem sempre alcançados pelos meios executivos típicos, como multas, desconsideração da personalidade jurídica, fraude, v.g.), o que, infelizmente, ainda é comum no Brasil, em que ainda impera a denominada cultura de transgressões (Rodovalho, 2016, online).

Algumas medidas executivas atípicas são comumente encontradas em julgados dos Tribunais Estaduais, inclusive, o E. Tribunal de Justiça do Paraná (2020, s.p.), no agravo de instrumento no 0012034-88.2020.8.16.0000, julgado pela $7^{\text {a }}$ Câmara Cível, consignou entendimento recente (10/08/2020) direcionado à adoção de medidas atípicas como apreensão de Carteira Nacional de Habilitação (CNH), suspensão de passaporte, suspensão de cartões de crédito e bloqueio do CPF para transações financeiras.

Em caso interessante, a $6^{\text {a }}$ Câmara do E. Tribunal de Justiça do Paraná (2020, s.p.) fundamentou a reforma da 
sentença em sede de agravo de instrumento $\mathrm{n}^{\circ}$ 0010249-91.2020.8.16.0000, consignando que na maioria dos casos, é compatível a utilização de tais expedientes, mostrando-se proporcional e razoável em relação ao exercício de direitos fundamentais, para estimular o devedor a adimplir obrigação de pagar quantia certa, quando a utilização dos meios ordinários se mostrar ineficiente, considerando "o dever do Poder Judiciário de conferir efetividade às suas decisões". O Tribunal consignou, ainda, que o executado demonstrou em redes sociais ter vida confortável e luxuosa, incompatível com a inadimplência espelhada nos autos.

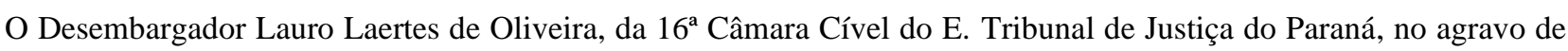
instrumento $\mathrm{n}^{\circ}$ 0024168-21.2018.8.16.0000 (2018, s.p.), asseverou que a medida precisa ser adequada, ou seja, deve-se optar por meios que tenham condições de promover, com certo grau de probabilidade, o resultado almejado, competindo ao juiz ponderar os interesses das partes, de modo que as vantagens na utilização da medida atípica escolhida superem as desvantagens do seu uso.

Importante asseverar que, caso o exequente faça o requerimento de aplicação de medidas executivas atípicas coercitivas, sabidamente infrutíferas para a satisfação do crédito, simplesmente com o intuito de prejudicar o executado (ex: quando apresenta caução notoriamente inidônea para prosseguimento da execução, cfe. art. 525, §10 ou; quando o contexto em que efetivada a averbação pelo exequente indicar que ele o fez sobretudo motivado pela intenção de prejudicar o executado" REsp 1694820/DF - na hipótese do art. 828 do CPC ), agirá com evidente má-fé processual (art. 77, I e II do CPC) e pode, inclusive, ser condenado à indenização por danos processuais.

Conforme afirma Marcelo Abelha Rodrigues (2020, online), caso mostre-se evidente que o executado não possui patrimônio, nem explícito e nem ocultado, não haverá medida atípica mágica que fará brotar patrimônio excutível onde ele não existe, e para tais casos não resta outra solução senão a suspensão do processo (art. 921, III) ou que o exequente requeira a conversão em execução contra devedor insolvente (art. 1052 do CPC combinado com o art. 748 e ss do CPC/73), aliás, algo pouquíssimo explorado no país e que seria de enorme utilidade se fosse mais incrementado.

Insta destacar que o art. 139, IV do CPC não só pode ser invocado pelo exequente, mas também pelo executado, quando pretende se desonerar da obrigação. Significa dizer que, quando o executado pretende a fungibilização de uma medida típica (leilão, por exemplo) por uma medida atípica como uma dação em pagamento (adjudicação inversa), desde que respeitado o contraditório do exequente, não há nenhuma vedação de que o dispositivo seja invocado pelo executado.

É por essa perspectiva que se pode pensar na aplicação dos princípios da menor onerosidade ao executado e da cooperação em consonância com o princípio da efetividade e do resultado no processo de execução. Enquanto ao Estado-juiz impera o dever de conceder a tutela jurisdicional efetiva ao exequente, com a aplicação do art. 139, IV do CPC (consideradas as peculiaridades do caso concreto a fim de resguardar direitos fundamentais), deve o exequente atuar de forma cooperativa e se reconhecer o princípio da menor onerosidade do executado, quando este assume a conduta de adimplir a obrigação.

Verifica-se que os princípios da execução em confluência com a legislação pátria, demonstram que a adoção do modelo atípico das medidas executivas busca conferir efetividade e garantir o resultado útil ao processo, concedendo ao exequente o equivalente ao direito inadimplido e garantindo ao executado a preservação de seus direitos fundamentais e a possibilidade de adimplir a obrigação de forma menos gravosa.

\subsection{A aplicação das medidas atípicas e o entendimento do Superior Tribunal de Justiça}

$\mathrm{Na}$ direção do processo, cumpre ao órgão jurisdicional assegurar às partes igualdade de tratamento (art. $5^{\circ}, \mathrm{I}, \mathrm{CF}$ ), elemento indissociável do processo justo (art. $5^{\circ}, \mathrm{LIV}, \mathrm{CF}$ ). Na esteira do direito fundamental à tutela jurisdicional adequada, efetiva e prestada em tempo razoável. Cabe ao juiz o dever de conduzir o processo, interpretar a legislação processual civil em conformidade com os direitos fundamentais processuais, preferindo para solução dos casos o sentido legal que: concretize de 
maneira ótima os direitos fundamentais. Cumpre-lhe ainda prevenir ou reprimir qualquer ato contrário à dignidade da justiça (arts. 80 e 772, CPC) e tentar conciliar as partes a qualquer tempo (arts. 334 e 359, CPC) (Medina, 2017, p. 284).

Os artigos 497 e 498 do CPC em associação com seus artigos 536, $\S 1^{\circ}$ e 538 , $\S 3^{\circ}$, oferecem ao juiz um instrumental jurídico-processual destinado à superação de barreiras à plena efetividade das decisões judiciárias. Tais dispositivos autorizam o juiz a exercer legítimas pressões psicológicas sobre o sujeito condenado por obrigação de fazer, de não fazer ou de entregar coisa certa para que cesse sua resistência contrária ao direito e cumpra a obrigação - chegando ao ponto de autorizá-lo, ainda, em caso de o obrigado perseverar em sua renitência, a impor providências que assegurem a obtenção do resultado prático equivalente ao do adimplemento. Isso significa diversificar as técnicas de busca de resultados mediante a execução judicial, autorizando-se o juiz a lançar mão de enérgicas medidas coercitivas, lá onde as sub-rogatórias não tenham como atuar ou efetivamente não atuem (Dinamarco, 2020, p. 382).

$\mathrm{O}$ art. 139, IV, CPC, explicita os poderes de imperium conferidos ao juiz para concretizar suas ordens. A regra se destina tanto a ordens instrumentais (aquelas dadas pelo juiz no curso do processo, para permitir a decisão final, a exemplo das ordens instrutórias no processo de conhecimento, ou das ordens exibitórias na execução) como a ordens finais (consistentes nas técnicas empregadas para a tutela da pretensão material deduzida) (Marinoni, 2017, p. 284).

Ao juiz cabe adequar o procedimento às necessidades do conflito, para tutelar de modo mais efetivo a pretensão que é deduzida. Na medida em que o princípio da atipicidade é aplicado, algumas situações são constatadas:

(a) a participação do juiz na elaboração da solução jurídica dos litígios passa a ser mais intensa; (b) a atividade jurisdicional deve proporcionar aos demandantes respostas capazes de propiciar uma tutela mais aproximada possível da pretensão violada, bem como de impedir que a violação ocorra (ex., art. 497 do CPC); (c) ante a multiplicidade e a complexidade das situações litigiosas que podem ser levadas a juízo, tais mecanismos não podem ser previstos num rol taxativo, numerus clausus, pois há risco de se excluir direitos igualmente merecedores de tutela e; (d) as medidas executivas que podem ser postas em prática podem não ser aquelas requeridas pelas partes, necessariamente, porque o juiz pode constatar a viabilidade de um meio executivo mais adequado à satisfação (fim) da pretensão do exequente (Medina, 2020, p. 1100).

O dever de respeito aos direitos fundamentais na aplicação da medida atípica é indispensável para a consecução do princípio da legalidade e do devido processo legal, sendo que o atual modelo legislativo (mais aberto), sobreleva essa necessária interação e, mesmo, interpenetração entre doutrina e jurisprudência, pois confere um maior poder ao juiz, e, justamente por isso, exige da jurisprudência uma postura responsável e prudente, interagindo e confluindo com a doutrina, evitando os perigos do subjetivismo ou do decisionismo. E ambos - doutrina e jurisprudência - beneficiam-se dessa relação, mesmo quando há necessidade de criticar e apontar erros (Rodovalho, 2020, online).

A direção do processo pelo juiz no Estado Constitucional caracteriza-se por ser uma direção que se pauta pela condução paritária do processo e pela assimétrica decisão da causa, significa dizer que o juiz está no mesmo nível das partes na condução da causa, tendo ele mesmo de observar o contraditório como regra de conduta, alocando-se em uma posição acima das partes apenas quando impõe a sua decisão. O juiz do processo civil contemporâneo é paritário no diálogo e assimétrico na decisão da causa. É um juiz que tem a sua atuação pautada pela regra da cooperação (Marinoni; Arenhart; Mitidiero, 2017, p. 283).

Assim, o Código de Processo Civil de 2015 adota um modelo presidencial cooperativista (arts. $6^{\circ}, 139$ e 772, todos do CPC/2015), em que se expande o papel presidencial (diretivo) do juiz. Antes, exclusivamente no controle da relação processual e na tomada de decisões. Agora, como órgão colaborativo, cooperador, a trabalhar em conjunto com as partes para que se alcance o melhor resultado possível, especialmente no âmbito da execução. Este modelo, catalisado pelo contraditório (artigos $9^{\circ}$ e 10 do CPC), impõe ao magistrado outros quatro deveres além do decidir quais sejam:

a) dever de esclarecimento: o julgador deve esclarecer-se junto às partes acerca das dúvidas que tenha em relação às 
alegações, pedidos e fatos, de modo a evitar que a decisão se dê com base nas regras sobre ônus da prova (vide art.139, VIII, do CPC/2015); b) dever de consulta: deve ser assegurado aos litigantes o direito de influenciar o julgador na solução da controvérsia, ainda que lhe seja lícito conhecer da questão oficiosamente; não se admite, em regra, a prolação de "decisões surpresa", sem que as partes a tenham previamente debatido (vide art. 10 do CPC/2015); c) dever de prevenção: consiste no dever de o juiz apontar as deficiências das postulações das partes, a fim de que possam vir a ser supridas e o processo alcance resultado mais efetivo (vide art. 139, IX, do CPC/2015); e d) dever de auxílio: consiste no dever de o magistrado auxiliar as partes na remoção de dificuldades ao exercício dos seus direitos, no cumprimento de ônus ou deveres processuais, e na efetivação dos comandos emitidos, inclusive sugerindo alterações nas condutas processuais eleitas (v.g.., em decisão que ordena a emenda da inicial executiva na forma art. 801 do CPC/2015, o juiz deve não só apontar expressamente o que deve ser corrigido, como também sugerir a readequação da via nos casos em que houve uma medida processual mais adequada ou útil para a tutela do direito material em debate) (Gajardoni; Dellore; Roque; Jr, 2018, p. 31).

A Escola Nacional de Formação e Aperfeiçoamento de Magistrados (ENFAM 48), estabelece que o art. 139, IV, do CPC consigna um poder geral de efetivação e permite a aplicação de medidas atípicas para garantir o cumprimento de qualquer ordem judicial, inclusive no âmbito do cumprimento de sentença e no processo de execução baseado em títulos extrajudiciais.

Sobre as medidas para efetivação das decisões judiciais, Nelson Nery afirma que a direção do processo implica no exercício de poder e de autoridade sobre as partes, os intervenientes e os auxiliares da Justiça, no processo. O texto normativo prevê que pode o juiz exercer o poder procedendo por raciocínio indutivo, obrigar as partes e os sujeitos da relação processual aos comandos que irradiam de sua autoridade, mesmo que esteja provisoriamente no exercício do poder. O desvio que macularia o poder de mando é a arrogância, que pode tornar abusivo o mando, pois o poder da autoridade não é absoluto (Nery Junior; Nery, 2020, p. 547).

Por esse contexto, é possível aduzir que as medidas executivas atípicas são verdadeiras medidas de efetivação das decisões judiciais, sendo que o ordenamento jurídico impõe normas limitadoras do exercício dos poderes do magistrado na aplicação dessas medidas, tanto pela análise dos princípios que norteiam a execução, quanto pela legislação constitucional e processual civil que estipula a aplicação subsidiária das referidas medidas.

Nessa linha, o contraditório substancial deve ser especialmente considerado em fase de execução, com a correta intimação do executado para pagamento do débito ou para nomear os bens suficientes para adimpli-lo, para contribuir com a adoção das medidas mais qualificadas para a produção do resultado útil ao processo, assim como para a formação da convicção do magistrado para a devida elaboração da fundamentação da decisão judicial, prevista no art. 489 do CPC.

A obrigatoriedade da fundamentação da decisão judicial consubstanciada no art. 489 do CPC, trata de verdadeiro limite à atividade jurisdicional, inclusive, em fase de execução, vez que seu $\S 1^{\circ}$, incisos I e II estipulam que não se considera fundamentada qualquer decisão judicial que se limite à indicação, à reprodução ou à paráfrase de ato normativo, sem explicar sua relação com a causa ou a questão decidida e que, emprega conceitos jurídicos indeterminados, sem explicar o motivo concreto de sua incidência no caso.

Significa dizer que, na aplicação das medidas executivas atípicas, as peculiaridades do caso concreto devem ser analisadas pelo juiz, com o objetivo de justificar sua adoção, não podendo se limitar a adotar conceitos jurídicos indeterminados e não indicar a reação entre ato normativo e a causa ou questão decidida.

Relevante limite para a aplicação do art. 139, IV do CPC foi estabelecido pelo Superior Tribunal de Justiça, que consigna a impossibilidade de adoção dos meios executivos atípicos contra devedor sem sinais de ocultação patrimonial. A Ministra Nancy Andrighi aduziu que o juiz deve intimar previamente o executado para pagar o débito ou apresentar bens destinados a saldá-lo, seguindo-se aos atos de expropriação típicos, exigindo, ainda, a fundamentação a partir das circunstâncias específicas do caso; o esgotamento prévio dos meios típicos de satisfação do crédito exequendo (cfe. REsp 1.782.418 e REsp 1.788.950).

No REsp 1.782.418 (Brasil, 2019), a Ministra Nancy Andrighi consignou que as modernas regras de processo, mesmo 
que respaldadas pela "busca da efetividade jurisdicional não podem se distanciar dos ditames constitucionais, apenas sendo possível a implementação de comandos não discricionários ou que restrinjam direitos individuais de forma razoável." O julgado salienta, ainda, que a aplicação dos meios executivos atípicos depende de decisão que contenha fundamentação adequada às especificidades da hipótese concreta, com observância do contraditório substancial e do postulado da proporcionalidade.

Sobre a aplicação de medidas executivas atípicas, em recente julgado, o Superior Tribunal de Justiça julgou HC 597.069/SC (Brasil, 2020), sobre controvérsia em torno da legalidade da decisão que determinou a suspensão da Carteira Nacional de Habilitação $(\mathrm{CNH})$ e a apreensão do passaporte da paciente no curso do processo de execução por título extrajudicial decorrente de contrato de locação comercial celebrado entre pessoas físicas. No caso, a devedora pretendia fixar residência fora do país, o que tornaria inalcançável seu patrimônio, o que resultou no entendimento pela razoabilidade da adoção das referidas medidas, limitadas temporalmente até a indicação de bens à penhora ou de realização de ato constritivo.

No REsp 1733697/RS, o Superior Tribunal de Justiça (Brasil, 2018), sobre a admissibilidade do uso da técnica executiva de desconto em folha da dívida de natureza alimentar quando há anterior penhora de bens do devedor, ponderou entre a máxima efetividade da execução e a menor onerosidade do devedor e entendeu pela possibilidade do desconto em folha parcelado, além da expropriação de bens penhorados.

No caso do julgado acima, a obrigação de natureza alimentar era devida pelo genitor há mais de vinte e quatro anos, com valor nominal superior a um milhão e trezentos mil reais e já tinha sido objeto de sucessivas impugnações do devedor, sendo admissível o deferimento do desconto em folha de pagamento do débito, parceladamente e observado o limite de $10 \%$ sobre os subsídios líquidos do devedor, observando-se que, se adotada apenas essa modalidade executiva, a dívida somente seria inteiramente quitada em 60 (sessenta) anos, motivo pelo qual se deve admitir a combinação da referida técnica subrogatória com a possibilidade de expropriação dos bens penhorados.

É evidente que não são apenas essas as medidas que tem sido adotadas pelos Tribunais, podendo-se citar o corte de energia elétrica de órgãos públicos, suspensão de serviço de redes sociais, sequestro de verbas públicas em demandas de saúde, proibição do uso da área de lazer pelo condômino inadimplente.

A doutrina diverge na avaliação dos poderes conferidos ao juiz pelo art. 139, IV do CPC. Para Gajardoni (2015, online), trata-se de potencialização do dispositivo, em uma revolução silenciosa da execução por quantia, na qual sua interpretação pode trazer resultados positivos para esfera da execução. Já para Streck e Nunes (2016, online) o dispositivo dá poderes ilimitados ao juiz para criar medidas inominadas, advertindo que a atipicidade não significa a concessão de uma "carta branca ao arbítrio" e frisam o perigo de restrição aos direitos fundamentais com amparo e autorização judicial.

O artigo 139, IV do CPC evidentemente consigna um maior espectro de possibilidades para a concessão da tutela jurisdicional efetiva, mas não pode servir como fundamento para decisões arbitrárias e autoritárias, que podem culminar em restrição de direitos fundamentais. Em outras palavras, o juiz deve aplicar o direito ao caso concreto, sendo-lhe vedado substituir o legislador, pois a figura do judge made law é incompatível com o sistema brasileiro da tripartição de poderes (RT 604/43). O juiz deve aplicar a lei e não revogá-la a pretexto de atingir um ideal subjetivo de justiça (RTJ 103/1262) (Nery Júnior, Nery, 2020, p. 561).

Para Calmon de Passos (2003, p. 93), o processo de produção do Direito é sempre dependente da realidade social que busca ordenar e a ela funcionalmente se vincula, objetivando alcançar segurança, mediante a predeterminação e institucionalização de modelos ou esquemas de solução de conflitos coercitivamente aplicáveis aos casos concretos.

Dessa forma, diante da análise da legislação e da jurisprudência recente do Superior Tribunal de Justiça, é possível verificar a aplicação de um poder geral de efetivação da tutela executiva emanado do art. 139, IV do CPC, rompendo com o dogma da tipicidade, tornando inquestionável que a adoção das medidas executivas atípicas pelo magistrado, desde que de 
forma subsidiária e pautada pelos limites normativos e jurisprudenciais, atua com o objetivo de concretizar o direito fundamental à tutela jurisdicional efetiva.

\section{Considerações Finais}

A Constituição Federal Brasileira (CF, art. 5 $5^{\circ}$ XXXV e LXXVIII), assim como o Código de Processo Civil (art. $4^{\circ}$ e $8^{\circ}$ ), preveem expressamente que os jurisdicionados têm o direito de obter a solução integral do mérito, incluindo a atividade satisfativa e em prazo razoável. A norma processual civil estabeleceu meios de natureza coercitiva indireta para auxiliar na satisfação do crédito do exequente, verificando-se uma ampliação dos poderes do juiz e uma flexibilização do processo por meio da possibilidade de adoção de medidas executivas atípicas, nos termos do art. 139, inciso IV do CPC, o que denota a existência do direito fundamental do exequente à satisfação efetiva e específica da tutela jurisdicional pretendida.

Os princípios fundamentais e setoriais ou informativos do processo de execução são norteadores da atividade executiva e devem ser considerados como verdadeiros balizadores da decisão judicial quando da aplicação das medidas executivas atípicas, especialmente, quando analisado pelo aspecto da dignidade da pessoa humana, legalidade, devido processo legal, contraditório, motivação, cooperação e pelo princípio da menor onerosidade do executado.

Os princípios da menor onerosidade ao executado e da cooperação em consonância com o princípio da efetividade e do resultado no processo de execução, devem ser devidamente sopesados para que o Estado-juiz concretize o dever de conceder a tutela jurisdicional efetiva ao exequente, com a aplicação do art. 139, IV do CPC, ocasião em que deve o exequente agir com cooperação quando reconhecida a postura do executado que adota a conduta de adimplir a obrigação.

As medidas executivas atípicas são verdadeiras medidas de efetivação das decisões judiciais, com a limitação do exercício jurisdicional por meio das normas, tanto pela análise dos princípios que norteiam a execução, quanto pela legislação constitucional e processual civil que estipulam a aplicação subsidiária das referidas medidas executivas atípicas.

O contraditório substancial em fase de execução ganha destaque, assim como a obrigatoriedade de fundamentação da decisão judicial, com o fim de estabelecer critérios e apontar as medidas mais qualificadas para a produção do resultado útil ao processo no caso concreto, assim como para a formação da convicção do magistrado para a devida elaboração da fundamentação da decisão judicial, prevista no art. 489 do CPC.

O Superior Tribunal de Justiça estabeleceu limites à aplicação do art. 139, IV do CPC, por meio da previsão de impossibilidade de adoção dos meios executivos atípicos contra devedor sem sinais de ocultação patrimonial; bem assim que seja garantido o contraditório do executado; com fundamentação judicial a partir das circunstâncias específicas do caso; esgotamento prévio dos meios típicos de satisfação do crédito exequendo.

O Supremo Tribunal Federal destacou que a legislação processual civil moderna é respaldada pela busca da efetividade jurisdicional, mas não deve se distanciar das normas constitucionais, não só evitando a realização de comandos que não sejam discricionários ou que restrinjam direitos individuais, mas que garantam a aplicação do postulado da proporcionalidade e razoabilidade.

Considerando os julgados analisados em relação às medidas atípicas consubstanciadas em apreensão e suspensão de $\mathrm{CNH}$, suspensão de passaporte, suspensão de cartões de crédito, proibição de contratação de novos financiamentos, desconto em folha de pagamento (quando se tratar de verba de natureza alimentar), observaram critérios normativos específicos para cada caso concreto, principalmente, pelo contraditório substancial efetivo e pela fundamentação específica da decisão, visando a busca da tutela jurisdicional efetiva, sem violação de direitos fundamentais do executado.

$\mathrm{O}$ art. 139, IV do CPC, desde que de forma subsidiária e observados os critérios legais e jurisprudenciais pode ser invocado pelo exequente, assim como pelo executado, quando manifestar o interesse de adimplir obrigação, ou seja, o magistrado deve considerar a proposta do executado que pretende a fungibilização de uma medida típica por uma medida 
atípica, desde que observado o contraditório substancial.

Portanto, de acordo com a legislação nacional e da jurisprudência recente do Superior Tribunal de Justiça, a aplicação de um poder geral de efetivação da tutela executiva oriunda do art. 139, IV do CPC, de fato, rompe com o dogma da tipicidade e torna imperiosa a adoção das medidas executivas atípicas pelo magistrado, desde que nos limites normativos para garantia da consecução do direito fundamental à tutela jurisdicional efetiva do exequente e com o devido respeito aos direitos fundamentais do executado.

\section{Referências}

Araújo, F. C. de. (2016). Curso de Processo Civil: parte geral. (Tomo I). Malheiros.

Câmara, A. F. (2020). O Novo Processo Civil brasileiro (6a ed.). Atlas.

Câmara, A. F. (2016). O princípio da patrimonialidade da execução e os meios executivos atípicos: lendo o art. 139, IV, do CPC. Revista Diálogos, 2(1), 88-9. http://ojs.fapce.edu.br/index.php/dialjurifap/article/download/36/5.

Dinamarco, C. R. (2020). Instituições de Direito Processual Civil. v. 1 (10a ed.). Malheiros.

Gajardoni, F. F. (2015). A revolução silenciosa da execução por quantia. Revista JOTA. https://www.jota.info/opiniao-e-analise/artigos/a-revolucao-silenciosada-execucao-por-quantia-24082015.

Gajardoni, F. F., Dellore, L., \& Roque, A. V., Jr., Z. D. de. O. (2018). Execução e recursos: comentários ao CPC 2015 (livro eletrônico). 3(2). Forense; Método.

Godoy, A. S. (1995). Introdução à pesquisa qualitativa e suas possibilidades. RAE-Revista de Administração de Empresas, 35(2), 57-63.

Guimarães, M. F. (2020). Medidas executivas atípicas e parâmetros de aplicabilidade: diretrizes do STJ. Revista Consultor Jurídico. https://www.conjur.com.br/2020-dez-11/mariana-guimaraes-medidas-executivas-atipicas.

Leborgne, A. R. I. In: Leborgne, A., Putman, E. Les Obstacles à L'execution Forcée: Permanence et Evolution. (2009). Paris: Éditions Juridiques et Techniques.

Medina, J. M. C. (2020). Curso de direito processual civil moderno [livro eletrônico] (5a ed.) Thomson Reuters Brasil, 2020.

Nery Junior, N., \& Nery, R. M. de. A. (2020). Código de Processo Civil comentado. (19a ed.). Thomson Reuters Brasil.

Passos, J. J. C. de. (2003). Direito, Poder, Justiça e Processo: julgando os que nos julgam. Forense.

Pereira, A. S. et. al. (2018). Metodologia da pesquisa científica. UFSM. https://repositorio.ufsm.br/bitstream/handle/1/15824/Lic_Computacao_MetodologiaPesquisa-Cientifica.pdf?sequence $=1$.

Rodovalho, T. (2016). O necessário diálogo entre a doutrina e a jurisprudência na concretização da atipicidade dos meios executivos. Revista JOTA. https://www.jota.info/opiniao-e-analise/artigos/o-necessario-dialogo-entre-doutrina-e-jurisprudencia-na-concretizacao-da-atipicidade-dos-meios-executivos21092016.

Rodrigues, M. A. (2020). O que fazer quando o exequente é um patife? O art. 139, IV do CPC também pode ser invocado pelo executado em seu favor? Revista Migalhas. https://migalhas.uol.com.br/depeso/323884/o-que-fazer-quando-o-exequente-e-um-patife-o-art-139-iv-do-cpc-tambem-pode-ser-invocadopelo-executado-em-seu-favor.

Streck, L. L., \& Nunes, D. (2016). Como interpretar o artigo 139, IV, do CPC? Carta branca para o arbítrio? Revista Consultor Jurídico. http://www.conjur.com.br/2016-ago-25/senso-incomum-interpretar-art-139-iv-cpc-carta-branca-arbitrio.

Superior Tribunal de Justiça. (2019). Não é possível adotar meios executivos atípicos contra devedor sem sinais de ocultação patrimonial. http://www.stj.jus.br/sites/portalp/Paginas/Comunicacao/Noticias/Nao-e-possivel-adotar-meios-executivos-atipicos-contra-devedor-sem-sinais-de-ocultacaopatrimonial.aspx.

Superior Tribunal de Justiça. (2019). Recurso Especial n. 1782418/RJ, Rel. Ministra Nancy Andrighi. Terceira Turma. Julgado em 23/04/2019, DJe 26/04/2019.

https://processo.stj.jus.br/processo/pesquisa/?src=1.1.3\&aplicacao=processos.ea\&tipoPesquisa=tipoPesquisaGenerica\&num_registro=201803135957.

Superior Tribunal de Justiça (2020). Habeas Corpus n. 597.069/SC, Rel. Ministro Paulo de Tarso Sanseverino, Terceira Turma. Julgado em 22/09/2020. DJe $25 / 09 / 2020$

https://processo.stj.jus.br/processo/pesquisa/?src=1.1.3\&aplicacao=processos.ea\&tipoPesquisa=tipoPesquisaGenerica\&num_registro=202001725432.

Superior Tribunal de Justiça. (2018). Recurso Especial n. 1733697/RS, Rel. Ministra Nancy Andrighi, Terceira Turma. Julgado em 11/12/2018. DJe $13 / 12 / 2018$.

https://processo.stj.jus.br/processo/pesquisa/?src=1.1.3\&aplicacao=processos.ea\&tipoPesquisa=tipoPesquisaGenerica\&num_registro=201800510205. 
Research, Society and Development, v. 10, n. 4, e21810414018, 2021

(CC BY 4.0) | ISSN 2525-3409 | DOI: http://dx.doi.org/10.33448/rsd-v10i4.14018

Tribunal de Justiça do Paraná. (2020). $7^{\text {a }}$ Câmara Cível - 0012034-88.2020.8.16.0000. Ponta Grossa. Rel.: Desembargador Mário Luiz Ramidoff - Julgado em: 07.08.2020. Data da Publicação: 10/08/2020. https://portal.tjpr.jus.br/jurisprudencia/j/4100000012917981/Ac\%C3\%B3rd\%C3\%A3o-001203488.2020.8.16.0000\#.

Tribunal de Justiça do Paraná. (2020). 6a Câmara Cível - 0010249-91.2020.8.16.0000. Curitiba. Rel.: Desembargador Renato Lopes de Paiva. Julgado em: 06.07.2020. Data da Publicação: 06/07/2020. https://portal.tjpr.jus.br/jurisprudencia/j/4100000012806081/Ac\%C3\%B3rd\%C3\%A3o-001024991.2020.8.16.0000\#.

Tribunal de Justiça do Paraná. (2018). 16ª Câmara Cível - 0024168-21.2018.8.16.0000. Apucarana. Rel: Des. Lauro Laertes de Oliveira. Unân. Julgado em: 19.09.2018. Data da Publicação: 22/09/2018. https://portal.tjpr.jus.br/jurisprudencia/j/4100000006640521/Ac\%C3\%B3rd\%C3\%A3o-002416821.2018.8.16.0000\#. 